\title{
Analisis Faktor yang Mempengaruhi Minat Tenaga Kerja Wanita Bekerja di PTPN X Unit Industri Bobbin Kecamatan Arjasa Kabupaten Jember
}

\author{
(Factor Analysis that Influences the Interest of Female Worker in PTPN X Bobbin \\ Industrial Unit of Arjasa District of Jember Regency)
}

\author{
Maktubatul Hasanah, P. Edi Suswandi, Duwi Yunitasari* \\ Jurusan Ilmu Ekonomi Studi Pembangunan, Fakultas Ekonomi dan Bisnis, Universitas Jember (UNEJ) \\ Jln. Kalimantan 37, Jember 68121 \\ E-mail: duwiyunita.feb@unej.ac.id
}

\begin{abstract}
Abstrak
Kabupaten Jember merupakan daerah penghasil tembakau terbaik di dunia dan menyerap tenaga kerja wanita. Tujuan dari penelitian ini adalah menganalisis variabel pendapatan, umur, pendidikan dan jumlah tanggungan terhadap minat tenaga kerja wanita bekerja di PTPN X Unit Industri Bobbin. Metode analisis yang digunakan adalah Ordinary Least Squares (OLS) dan model yang digunakan Binary Logistic Regression dengan menggunakan data primer yang meliputi data keputusan tenaga kerja, pendapatan, umur, pendidikan dan jumlah tanggungan. Sampel yang diambil sebanyak 100 responden. Pengambilan sampel dihitung menggunakan rumus proportional stratified random sampling. Hasil penelitian menunjukkan bahwa pendapatan, umur, pendidikan berpengaruh negatif dan signifikan, sedangkan jumlah tanggungan tidak berpengaruh terhadap minat tenaga kerja wanita bekerja di PTPN X Unit Industri Bobbin.
\end{abstract}

Kata kunci: Minat tenaga kerja wanita, Pendapatan, Umur, Pendidikan, dan Jumlah Tanggungan.

\begin{abstract}
Jember Regency is the best tobacco producing region in the world and absorbs female workers. The purpose of this study was to analyze the variables of income, age, education and the number of dependents on the interest of female workers working at PTPN X Industrial Unit Bobbin. The analytical method used is Ordinary Least Squares (OLS) and the model used by Binary Logistic Regression using primary data which includes data on labor decisions, income, age, education and number of dependents. Samples taken were 100 respondents. Sampling was calculated using the proportional stratified random sampling formula. The results showed that income, age, education had a negative and significant effect, while the number of dependents did not affect the interest of female workers working at PTPN X Bobbin Industrial Unit.
\end{abstract}

Keywords: Interest of female workers, Income, Age, Education, Family members.

\section{Pendahuluan}

Pembangunan suatu bangsa memerlukan aset pokok yang disebut sumber daya, baik sumber daya alam maupun sumber daya manusia. Dua sumber daya tersebut sangat penting dalam menentukan keberhasilan suatu pembangunan. Antara kedua sumber daya tersebut sumber daya manusialah yang paling penting (Notoatmodjo, 2003:2). Berbicara masalah sumber daya manusia dapat kita lihat dari dua aspek, yaitu kuantitas dan kualitas. Kuantitas menyangkut dengan jumlah sumber daya manusia yang kurang penting kontribusinya dalam pembangunan, bahkan kuantitas sumber daya manusia tanpa disertai dengan kualitas yang baik akan menjadi beban pembangunan suatu bangsa, karena kualitas menyangkut mutu sumber daya manusia, yang menyangkut kemampuan, baik kemampuan fisik maupun kemampuan nonfisik (kecerdasan dan mental). Oleh karena itu untuk kepentingan akselerasi suatu pembangunan di bidang apapun, maka peningkatan kualitas sumber daya manusia merupakan prasyarat utama. Kualitas sumber daya manusia ini menyangkut dua aspek juga, yakni aspek fisik dan aspek nonfisik yang menyangkut kemampuan bekerja, berpikir, dan keterampilan - keterampilan lain (Notoatmojo, 2003:3)

Negara dengan jumlah penduduk yang besar dan laju pertumbuhan yang tinggi sering mengalami masalah dalam hal penyerapan tenaga kerja. Masalah penduduk dalam pembangunan ekonomi sangat komplek, karena merupakan faktor pendorong maupun faktor penghambat laju pertumbuhan ekonomi suatu negara. Penduduk yang terlalu padat menimbulkan banyak pengangguran sedang penduduk yang terlalu jarang akan mengakibatkan kekurangan masalah tenaga kerja. (Latumaerissa, $2015:$ 42).

Kabupaten Jember merupakan salah satu kabupaten yang besar jumlah penduduknya. Berdasarkan data tahun 2016 jumlah penduduk laki-laki sebesar 1.182.817 juta jiwa dan jumlah penduduk perempuan sebesar 1.224.298 juta jiwa. Dari data tersebut dapat disimpulkan bahwa jumlah penduduk perempuan lebih besar dari pada jumlah penduduk laki-laki (Jember dalam angka, 2016). Kabupaten Jember terkenal sebagai salah satu kota penghasil tembakau terbaik di dunia. Tembakau sebagai bahan baku cerutu pernah mengalami jaman keemasan, yaitu pada tahun 1980-an. Jenis tembakau cerutu terdiri dari tembakau Sumatera/Deli, tembakau Vorstenlanden serta tembakau Besuki Na-Oogst produk Jember dan sekitarnya mampu menguasai pasar Eropa, bahkan pernah memiliki pasar di Amerika dan Afrika (Santoso, 2013:6). Melalui potensi tanaman tembakau ini, Kabupaten Jember telah lama terkenal dan melegenda sebagai "kota tembakau" yang merupakan salah satu daerah produsen dan penghasil tembakau terbesar dengan produk yang berkualitas. Tidak hanya di pasar nasional, bahkan telah lama Kota Jember dikenal di beberapa negara Eropa seperti

\footnotetext{
* Corresponding author
} 
Bremen (Santoso, 2013:8).

Teori Human Capital menyatakan bahwa, manusia bukan hanya sekedar sumber daya tetapi melainkan juga merupakan modal yang menghasilkan pengembalian (return) dan setiap pengeluaran yang dilakukan dalam rangka mengembangkan kualitas dan kuantitas modal tersebut merupakan kegiatan investasi. Asumsi dasar teori Human Capital menyatakan bahwa seseorang dapat meningkatkan pendapatannya melalui peningkatan pendidikan. Setiap tambahan satu tahun sekolah bearti, di satu pihak meningkatkan kemampuan kerja dan tingkat pengahsilan seseorang (Simanjuntak, 1998:38).

Meningkatnya hasil produksi tembakau setiap tahunnya bukanlah menjadi beban kepada masyarakat. Namun akan menjadi peluang untuk masyarakat dimana dapat mengurangi jumlah penduduk/tenaga kerja yang menganggur, karena tembakau yang dihasilkan tidak hanya berhenti dalam bentuk tembakau saja melainkan akan diolah untuk menjadi bentuk lainnya. Satu-satunya BUMN yang mengelola tembakau di Jember adalah PT. Perkebunan Nusantara X (PTPN X). Dalam upaya mengantisipasi persaingan pasar utamanya di luar negeri, selain memasarkan produk tembakau secara langsung, PTPN X juga mengembangkan melalui unit Industri Bobbin. Industri Bobbin membawa manfaat yang sangat besar, yaitu menyerap tenaga kerja. Berdasarkan data yang diperoleh terdapat total keseluruhan 2.721 jiwa dengan rincian 2.655 jiwa adalah tenaga kerja wanita sedangkan tenaga kerja laki-laki dengan jumlah 66 jiwa.

Hipotesis dalam penelitian ini bahwa, diduga terdapat pengaruh positif dan signifikan dari variabel pendapatan dan jumlah tanggungan. Sedangkan diduga terdapat pengaruh negatif dan signifikan terhadap variabel umur dan pendidikan.

\section{Metode}

\section{Rancangan atau desain penelitian}

Rancangan yang digunakan dalam penelitian ini adalah deskriptif eksplanatory. Dimana secara deskriptif menjelaskan mengenai suatu masalah kejadian secara fakta maupun realita. Sedangkan eksplanatory menerangkan suatu kejadian sebab akibat atau hubungan antar variabel. Dimana suatu kasus memiliki keunikan dan kemudian dicocokkan dengan teori-teori yang sesuai.

\section{Jenis dan Sumber Data}

Data yang digunakan dalam penelitian ini adalah data primer. Data primer adalah data yang langsung diperoleh dari observasi dan melakukan wawancara langsung kepada responden dengan kuisioner yang telah ditentukan.

\section{Populasi dan Sampel}

Populasi dalam penelitian ini adalah penduduk perempuan yang berdomisili di Kecamatan Arjasa. Sampel dalam penelitian ini adalah penduduk perempuan yang memutuskan berminat dan tidak berminat untuk bekerja di PTPN X Unit Industri Bobbin Kecamatan Arjasa Kabupaten Jember. Dalam penelitian ini diambil dari jumlah populasi penduduk perempuan Kecamatan Arjasa berdasarkan data tahun 2016 yang berjumlah 20.119 jiwa, dengan tingkat kesalahan 10\%.
Untuk menentukan besarnya jumlah sampel maka digunakan rumus Slovin sebagai berikut:

$$
\begin{gathered}
n=\frac{N}{1+N(e) 2} \\
n=\frac{20.119}{1+20.119(0,1) 2}=99,99
\end{gathered}
$$

Setelah diketahui sampel yang digunakan adalah 100 responden, maka akan dihitung menggunakan rumus proportional stratified random sampling yaitu teknik pengambilan sampel dengan cara memisahkan elemenelemen populasi dalam kelompok-kelompok yang disebut strata dan kemudian mengalokasikan sampel secara berimbang atau proporsional dengan besarnya strata ( Nasir, M. 2003 ). Berikut adalah rumus alokasi proportional :

$$
n i=\frac{N i}{N} \times n
$$

\begin{tabular}{|c|c|c|c|c|c|}
\hline No & Desa & Populasi & Perhitungan & Samp & Pemb \\
\hline 1 & $\begin{array}{l}\text { Kemu } \\
\text { ning } \\
\text { Lor }\end{array}$ & 4124 & $\begin{array}{c}4124 / 20119 x \\
100\end{array}$ & 20.49 & 20 \\
\hline 2 & $\begin{array}{l}\text { Darso } \\
\text { no }\end{array}$ & 3316 & $\begin{array}{c}3316 / 20119 x \\
100\end{array}$ & 16.49 & 16 \\
\hline 3 & Arjasa & 4279 & $\begin{array}{c}4279 / 20119 x \\
100\end{array}$ & 21.26 & 21 \\
\hline 4 & Biting & 2923 & $\begin{array}{c}2923 / 20119 x \\
100\end{array}$ & 14.53 & 15 \\
\hline 5 & $\begin{array}{l}\text { Candij } \\
\text { ati }\end{array}$ & 2600 & $\begin{array}{c}2600 / 20119 x \\
100\end{array}$ & 12.92 & 13 \\
\hline 6 & Kamal & 2877 & $\begin{array}{c}2877 / 20119 x \\
100\end{array}$ & 14.30 & 14 \\
\hline \multicolumn{2}{|c|}{ Jumlah } & 20.119 & & 99.99 & 100 \\
\hline
\end{tabular}

Tabel 1. Jumlah Sampel Penelitian

Sumber : Publikasi Kec. Arjasa 2016.

\section{Metode Analisis Data}

Analisis data dalam penelitian ini menggunakan Analisis regresi Ordinary Least Square (OLS) dengan model Logistic Regression Model (LRM). Dalam penelitian ini menggunakan model logistic regression untuk mengestimasi minat tenaga kerja wanita bekerja di PTPN X Unit Industri Bobbin berdasarkan faktor-faktor yang mempengaruhi.

Permasalahan yang akan diteliti yaitu minat tenaga kerja wanita (Y), dipengaruhi oleh Pendapatan keluarga (X1), Umur $\left(\mathrm{X}_{2}\right)$, Pendidikan $\left(\mathrm{X}_{3}\right)$ dan Jumlah Tanggungan $\left(\mathrm{X}_{4}\right)$.

$$
\mathrm{Y}=\mathrm{f}\left(\mathrm{X}_{1}, \mathrm{X}_{2}, \mathrm{X}_{3}, \mathrm{X}_{4},\right)
$$

Sehingga teknik estimasi yang digunakan dalam penelitian ini menghasilkan fungsi regresi sebagai berikut :

$$
\mathrm{Li}=\ln \left[\begin{array}{c}
1-P 1 \\
P i \frac{\dot{i}}{\dot{i}}
\end{array}\right]=\mathrm{b} 0+\mathrm{b}_{1} \mathrm{X}_{1}+\mathrm{b}_{2} \mathrm{X}_{2}+\mathrm{b}_{3} \mathrm{X}_{3}+\mathrm{b}_{4} \mathrm{X}_{4}+\mathrm{e}
$$

Dimana :

$\begin{array}{ll}\mathrm{Li} & \text { : Minat tenaga kerja wanita } \\ \mathrm{ln} & \text { : Logaritma natural } \\ \mathrm{P} & \text { : Probabilitas minat tenaga kerja wanita } \\ \mathrm{b} 0 & \text { : Nilai Konstanta } \\ \mathrm{X}_{1} & \text { : Pendapatan }\end{array}$


$\mathrm{X}_{2} \quad$ : Umur

$\mathrm{X}_{3} \quad$ : Pendidikan

$\mathrm{X}_{4} \quad$ : Jumlah Tanggungan

$\mathrm{b}_{1,2,3,4} \quad$ : Koefisien regresi

e : Error

\section{Hasil dan Pembahasan}

\section{Hasil}

Terdapat 100 responden yang dipilih untuk mewakili tenaga kerja baik yang bekerja di Industri Bobbin ataupun yang tidak bekerja di Industri Bobbin yang dipengaruhi oleh beberapa variabel yaitu pendapatan, umur, pendidikan dan jumlah tanggungan yang mana akan di perhitungkan hasilnya dengan menggunakan metode OLS model binary logistic regression. Hasil analisis terdapat pada Tabel 2.

Tabel 2. Hasil analisis model regersi logistik

\begin{tabular}{|c|c|c|c|c|}
\hline Variabel & Koefisien & Std.Error & z-statistic & Prob \\
\hline $\mathrm{C}$ & 16.77627 & 4.091394 & 4.100381 & 0.0000 \\
\hline PDN & $-1.46 \mathrm{E}-06$ & $3.94 \mathrm{E}-07$ & 3.716720 & 0.0002 \\
\hline UMR & -0.162666 & 0.075158 & $\begin{array}{c}- \\
2.164305\end{array}$ & 0.0304 \\
\hline PDD & -2.617515 & 0.767394 & 3.410912 & 0.0006 \\
\hline \multicolumn{2}{|c|}{$\begin{array}{l}\text { McFadden R-squared } \\
\text { LR statistic }\end{array}$} & $\begin{array}{l}0.356364 \\
0.860074 \\
51.15888\end{array}$ & 0.781944 & 0.4342 \\
\hline \multicolumn{2}{|c|}{ Prob (LR statistic) } & 0,000000 & & \\
\hline
\end{tabular}

Sumber: Data primer, diolah 2017

Berdasarkan hasil analisis regresi logit pada Tabel 2, maka diperoleh persamaan sebagai berikut ini :

$M T k=\ln \left(\frac{P i}{1-P i}\right)=b 0+i \mathrm{~b}_{1} \mathrm{PDN}+\mathrm{b}_{2} \mathrm{UMR}+\mathrm{b}_{3} \mathrm{PDD}+$

$\mathrm{b}_{4} \mathrm{JT}+\mathrm{e}$

$M T k=\ln \left(\frac{P i}{1-P i}\right)=16.77627-0,00000146 \quad \mathrm{PDN} \quad-$

$0.162666 \mathrm{UMR}-2.617515 \mathrm{PDD}+0.278657 \mathrm{JT}+\mathrm{e}$

\section{Uji Estimasi Parameter}

Interpretasi dari Tabel 2, dijelaskan pada poin 1,2,3, dan 4 yaitu sebagai berikut:

\section{Interpretasi Hasil}

Dalam melakukan interpretasi koefisien-koefisien dalam model regresi logit maka diaplikasikan dalam odd ratio (rasio kecenderungan). Interpretasi yang lebih berguna ialah interpretasi yang dinyatakan dalam "odds", yang diperoleh dengan mengambil antilog dari berbagai koefisien arah (Supranto, 2004:329). Rasio Odd ditulis sebagai $b$ atau Exp (b). Rasio Odd digunakan untuk mengetahui kecenderungan peluang suatu variabel. Berdasarkan hasil estimasi model logit ialah sebagai berikut:

\section{a. Odd Ratio Variabel Pendapatan}

Variabel pendapatan mempunyai koefisien regresi sebesar $-0,00000146$. Koefisien regresi tersebut dapat digunakan untuk memprediksi kemungkinan minat tenaga kerja wanita bekerja di Unit Industri Bobbin Kecamatan Arjasa Kabupaten
Jember. Hal ini dapat diinterpretasikan sebagai berikut:

$\mathrm{OR}=\mathrm{e}^{b i}$

$\mathrm{OR}=\mathrm{e}-0,00000146$

$\mathrm{OR}=\exp (-0,00000146)$

$\mathrm{OR}=0,99999854$

Nilai Odd Ratio variabel pendapatan sebesar 0,99999854 artinya setiap kenaikan pendapatan yang dihasilkan oleh keluarga, maka akan ada kemungkinan menurunnya minat tenaga kerja wanita untuk bekerja di Unit Industri Bobbin Kecamatan Arjasa Kabupaten Jember sebesar 0,99999854.

\section{b. Odd Ratio Variabel umur}

Variabel umur mempunyai koefisien regresi sebesar -0.162666. Koefisien regresi tersebut dapat digunakan untuk memprediksi kemungkinan minat tenaga kerja wanita bekerja di Unit Industri Bobbin Kecamatan Arjasa Kabupaten Jember. Hal ini dapat diinterpretasikan sebagai berikut:

$\mathrm{OR}=\mathrm{e}^{b i}$

$\mathrm{OR}=\mathrm{e}^{-0.162666}$

$\mathrm{OR}=\exp (-0.162666)$

$\mathrm{OR}=0,849874$

Nilai Odd Ratio variabel umur sebesar 0,849874 artinya semakin bertambah umur responden maka ada kemungkinan menurunnya minat tenaga kerja wanita untuk bekerja di Unit Industri Bobbin Kecamatan Arjasa Kabupaten Jember sebesar 0,849874 .

\section{c. Odd Ratio Variabel Pendidikan}

Variabel pendidikan mempunyai koefisien regresi sebesar -2.617515 . Koefisien regresi tersebut dapat digunakan untuk memprediksi kemungkinan minat tenaga kerja wanita untuk bekerja di Unit Industri Bobbin Kecamatan Arjasa Kabupaten Jember. Hal ini dapat diinterpretasikan sebagai berikut:

$\mathrm{OR}=\mathrm{e}^{b i}$

$\mathrm{OR}=\mathrm{e}^{-2.617515}$

$\mathrm{OR}=\exp (-2.617515)$

$\mathrm{OR}=0,072984$

Nilai Odd Ratiovariabel pendidikan sebesar 0,072984 artinya semakin tinggi tingkat pendidikan responden, maka ada kemungkinan menurunnya minat tenaga kerja wanita untuk bekerja di Unit Industri Bobbin Kecamatan Arjasa Kabupaten Jember sebesar 0,072984.

\section{d. Odd Ratio Variabel Jumlah Tanggungan}

Variabel jumlah tanggungan mempunyai koefisien regresi sebesar 0.278657 . Koefisien regresi tersebut dapat digunakan untuk memprediksi kemungkinan minat tenaga kerja wanita untuk bekerja di Unit Industri Bobbin Kecamatan Arjasa Kabupaten Jember. Hal ini dapat diinterpretasikan sebagai berikut:

$\mathrm{OR}=\mathrm{e}^{b i}$

$\mathrm{OR}=\mathrm{e}^{0.278657}$

$\mathrm{OR}=\exp (0.278657)$

$\mathrm{OR}=1,321354$

Nilai Odd Ratio variabel pendidikan sebesar 1,321354 artinya setiap bertambahnya jumlah tanggungan maka akan bertambah kemungkinan minat tenaga kerja wanita untuk bekerja di Unit Industri Bobbin Kecamatan Arjasa Kabupaten Jember sebesar 1,321354. 


\section{e. Uji Likelihood Ratio (LR)}

Berdasarkan hasil estimasi diatas, hasil LR statistik adalah sebesar 51.15888dengan probabilitas LR statistik sebesar 0,000000 lebih kecil dari $\alpha(0,05)$, sehingga hipotesis Ha dapat diterima. Hal ini berarti bahwa seluruh variabel independen yaitu pendapatan, umur, pendidikan dan jumlah tanggungan secara bersama-sama berpengaruh signifikan terhadap minat tenaga kerja wanita bekerja di Unit Industri Bobbin Kecamatan Arjasa Kabupaten Jember.

\section{Uji Wald (Uji Z)}

Uji Z-statistik juga disebut dengan uji wald. Uji Wald pada regresi dengan metode Maximum Likelihood (MLE) berfungsi

sebagai uji-t pada regresi dengan metode OLS.Uji ini bertujuan untuk mengetahui pengaruh variabel independen secara parsial terhadap variabel dependen. Parameter yang digunakan untuk uji Wald parsial penelitian ini adalah membandingkan antara nilai signifikansi dengan taraf nyata $5 \%$. Berdasarkan hasil pengolahan data pada Tabel 2, maka dapat dinyatakan bahwa:

a. Hasil uji Z pada tingkat kesalahan 5\% untuk pendapatan menunjukkan bahwa $\mathrm{z}$ hitung adalah sebesar -3.716720 dan probabilitas $z$ hitung sebesar 0,0002 lebih kecil dari $\alpha(0,05)$, sehingga $\mathrm{Ha}$ dapat terima. Hal ini menyatakan bahwa variabel pendapatan secara parsial berpengaruh sacara signifikan terhadap minat tenaga kerja wanita bekerja di Unit Industri Bobbin. Dengan nilai odd ratio sebesar 0,99999854. Artinya, semakin tinggi pendapatan yang diperoleh, maka probabilitas penduduk untuk bekerja di Unit Industri Bobbin semakin menurun sebesar 0,99999854 kali dari pada penduduk dengan pendapatan rendah.

b. Hasil uji $\mathrm{Z}$ pada tingkat kesalahan 5\% untuk umur menunjukkan bahwa $z$ hitung adalah sebesar -2.164305 dan probabilitas $\mathrm{z}$ hitung sebesar 0,0304 lebih kecil dari $\alpha(0,05)$, sehingga $\mathrm{Ha}$ dapat terima. Hal ini menyatakan bahwa variabel umur secara parsial berpengaruh sacara signifikan terhadap minat tenaga kerja wanita bekerja di Unit Industri Bobbin.Dengan nilai odd ratio sebesar 0,849874. Artinya, semakin bertambah umur tenaga kerja, maka probabilitas penduduk untuk bekerja di Unit Industri Bobbin semakin menurun 0,849874 kali dari pada penduduk yang berumur muda.

c. Hasil uji $\mathrm{Z}$ pada tingkat kesalahan $5 \%$ untuk pendidikan menunjukkan bahwa $\mathrm{z}$ hitung adalah sebesar -3.410912 dan probabilitas $z$ hitung sebesar 0,0006 lebih kecil dari $\alpha(0,05)$, sehingga $\mathrm{Ha}$ dapat terima. Hal ini menyatakan bahwa variabel pendidikan secara parsial berpengaruh sacara signifikan terhadap minat tenaga kerja wanita bekerja di Unit Industri Bobbin.Dengan nilai odd ratio sebesar 0,072984. Artinya, semakin tinggi tingkat pendidikan penduduk, maka probabilitas penduduk untuk bekerja di Unit Industri Bobbin semakin menurun sebesar 0,072984 kali dari pada penduduk yang berpendidikan rendah.

d. Hasil uji Z pada tingkat kesalahan 5\% untuk jumlah taggungan menunjukkan bahwa $\mathrm{z}$ hitung adalah sebesar 0.781944 dan probabilitas $\mathrm{z}$ hitung sebesar 0.4342 lebih besar dari $\alpha(0,05)$, sehingga Ho dapat terima. Hal ini menyatakan bahwa jumlah tanggungan secara parsial tidak berpengaruh sacara signifikan terhadap terhadap minat tenaga kerja wanita bekerja di Unit Industri Bobbin.

e. Nilai konstanta sebesar sebesar 16.77627. Artinya tanpa dipengaruhi pendapatan, umur, pendidikan dan jumlah tanggungan nilai penduduk untuk bekerja di Unit Industri Bobbin adalah sebesar 16.77627.

\section{Uji McFadden $\mathbf{R}^{2}$}

Nilai koefisien determinasi McFadden $\mathrm{R}^{2}$ digunakan untuk mengetahui besarnya kontribusi koefisien dari variabel pendapatan, umur, pendidikan, dan jumlah tanggungan terhadap minat tenaga kerja wanita bekerja di Unit Industri Bobbin. Berdasarkan hasil estimasi, didapatkan nilai McFadden $\mathrm{R}^{2}$ sebesar 0.860074 , artinya total variasi minat tenaga kerja wanita bekerja di Unit Industri Bobbin mampu dijelaskan oleh seluruh variabel independen $86,00 \%$ sedangkan sisanya $14,00 \%$ dijelaskan variabel lain di luar model.

\section{Uji Goodness of Fit}

Tabel 3. Hasil Uji Goodness of Fit

\begin{tabular}{|c|c|c|c|c|c|c|}
\hline & \multicolumn{3}{|c|}{ Estimed Equation } & \multicolumn{3}{|c|}{ Constant Probability } \\
\hline & $\begin{array}{l}\text { Dep } \\
=0\end{array}$ & $\begin{array}{l}\text { Dep } \\
=1\end{array}$ & Total & $\begin{array}{l}\text { Dep }= \\
0\end{array}$ & $\begin{array}{l}\text { Dep } \\
=1\end{array}$ & Total \\
\hline $\begin{array}{l}\mathrm{P}(\mathrm{Dep}=1)< \\
=\mathrm{C}\end{array}$ & 32 & 6 & 38 & 0 & 0 & 0 \\
\hline $\begin{array}{l}\mathrm{P}(\mathrm{Dep}=1)> \\
\mathrm{C}\end{array}$ & 8 & 54 & 62 & 40 & 60 & 100 \\
\hline Total & 40 & 60 & 100 & 40 & 60 & 100 \\
\hline Correct & 32 & 54 & 86 & 0 & 60 & 60 \\
\hline$\%$ Correct & $\begin{array}{c}80.0 \\
0\end{array}$ & $\begin{array}{c}90.0 \\
0\end{array}$ & 86.00 & 0.00 & $\begin{array}{c}100 . \\
00\end{array}$ & 60.00 \\
\hline$\%$ Incorrect & $\begin{array}{c}20.0 \\
0\end{array}$ & $\begin{array}{c}10.0 \\
0\end{array}$ & 14.00 & $\begin{array}{c}100.0 \\
0\end{array}$ & 0.00 & 40.00 \\
\hline Total Gain* & $\begin{array}{c}80.0 \\
0\end{array}$ & $\begin{array}{c}- \\
10.0 \\
0\end{array}$ & 26.00 & & & \\
\hline $\begin{array}{l}\text { Percent } \\
\text { Gain** }\end{array}$ & $\begin{array}{c}80.0 \\
0 \\
\end{array}$ & NA & 65.00 & & & \\
\hline
\end{tabular}

Sumber: Data primer, diolah 2017

Berdasarkan hasil uji Goodness of Fit pada Tabel 3 menunjukkan bahwa model dapat memprediksi 86 dari 100 minat tenaga kerja wanita bekerja di unit Industri Bobbin Kecamatan Arjasa Kabupaten Jember secara benar dan persentase keakuratan pemberian nilai dummy sebesar $86,00 \%$. Dari hasil tersebut diketahui bahwa nilai prediksi mendekati $100 \%$ atau lebih dari $75 \%$ yaitu $86 \%$ yang menjelaskan bahwa model tersebut benar.

\section{Pembahasan}

Setelah dilakukan pengujian secara simultan maka dapat diketahui hasil analisis regresi logistik pada penelitian ini menunjukkan bahwa variabel pendapatan, umur, pendidikan, dan jumlah tanggungan berpengaruh signifikan terhadap terhadap minat tenaga kerja wanita bekerja di Unit Industri Bobbin Kecamatan Arjasa Kabupaten Jember sebagai betikut:

\section{Pengaruh Pendapatan terhadap Minat Tenaga Kerja Wanita Bekerja di Unit Industri Bobbin}

Adapun hasil analisis regresi logistik menunjukkan bahwa 
variabel pendapatan berpengaruh signifikan dengan koefisien negatif terhadap minat tenaga kerja wanita bekerja di Unit Industri Bobbin Kecamatan Arjasa Kabupaten Jember. Artinya semakin tinggi pendapatan keluarga maka minat tenaga kerja wanita untuk bekerja di Unit Industri Bobbin akan semakin menurun dan begitupun sebaliknya.

Hasil penelitian ini mendukung hasil penelitian yang dilakukan oleh Yusnita (2007) yang menyatakan bahwa pendapatan berpengaruh signifikan dan bernilai negatif terhadap keputusan wanita menjadi penjual sayur. Artinya semakin tinggi pendapatan maka wanita lebih memutuskan untuk tidak menjadi penjual sayur dan sebaliknya jika pendapatan rendah maka perempuan lebih memutuskan menjadi penjual sayur.

Pendapatan adalah jumlah penghasilan riil dari salah satu anggota rumah tangga yang disumbangkan untuk memenuhi kebutuhan bersama maupun perseorangan dalam rumah tangga. Pendapatan keluarga berperan penting dalam menentukan keadaan ekonomi yang bersangkutan karena pada hakekatnya kesejahteraan keluarga tergantung pada besar kecilnya pendapatan keluarga (Simanjuntak, 1998:48)

\section{Pengaruh Umur terhadap Minat Tenaga Kerja Wanita Bekerja di Unit Industri Bobbin}

Adapun hasil analisis regresi logistik menunjukkan bahwa variabel umur berpengaruh signifikan dengan koefisien negatif terhadap minat tenaga kerja wanita bekerja di Unit Industri Bobbin Kecamatan Arjasa Kabupaten Jember. Artinya semakin bertambah umur tenaga kerja wanita maka minat untuk bekerja di Unit Industri Bobbin akan semakin berkurang dan begitupun sebaliknya.

Hasil penelitian ini mendukung hasil penelitian yang dilakukan oleh Wahyuni (2016) yang menyatakan bahwa variabel usia yang menunjukkan tanda negatif berarti semakin kecil minat seseorang untuk melakukan migrasi sirkuler yang mana sesuai dengan teori Ravenstein (1976) yang mengatakan bahwa penduduk yang masih muda banyak melakukan migrasi, dikarenakan tenaga masih kuat dan produktivitas dalam bekerja sangat baik.

Umur merupakan salah satu hal yang menentukan keaktifan seseorang dalam melakukan pekerjaan atau usahanya. Dilihat dari faktor umur partisipasi kerja dari seseorang cenderung sejalan dengan meningkatkan umur. Hal ini dapat dilihat dari usia produktif seseorang yang giat bekerja apabila dibandingkan dengan mereka yang berusia lanjut. Semakin lanjut usia seseorang maka kemampuan fisiknya semakin lama semakin berkurang (Simanjuntak, 1997:39)

\section{Pengaruh Pendidikan terhadap Minat Tenaga Kerja Wanita Bekerja di Unit Industri Bobbin}

Adapun hasil analisis regresi logistik menunjukkan bahwa variabel pendidikan berpengaruh signifikan dengan koefisien negatif terhadap minat tenaga kerja wanita bekerja di Unit Industri Bobbin Kecamatan Arjasa Kabupaten Jember. Artinya semakin tinggi pendidikan tenaga kerja wanita maka minat bekerja di Unit Industri Bobbin akan semakin menurun dan begitupun sebaliknya.

Hasil penelitian ini mendukung hasil penelitian yang dilakukan oleh Haryono (2016) yang menyatakan bahwa pendidikan berpengaruh negatif dan signifikan. Artinya semakin tinggi pendidikan seseorang maka akan semakin menurun minat seseorang untuk melakukan migrasi sirkuler dan penelitian yang dilakukan oleh Purnomo (2009) yang menyatakan bahwa tingkat pendidikan berpengaruh negatif dan signifikan, hal ini menunjukkan bahwa semakin tinggi tingkat pendidikan seseorang maka akan semakin rendah pula tingkat mobilitas orang tersebut.

Pendidikan merupakan salah satu bentuk investasi sumber daya manusia. pendidikan memberikan sumbangan secara langsung terhadap pertumbuhan pendapatan nasional melalui keterampilan dan produktifitas kerja (Tjiptoherijanto, 1997:30). Semakin rendah tingkat pendidikan masyarakat maka akan semakin sulit bagi masyarakat untuk mendapatkan pekerjaan dengan penghasilan yang lebih tinggi. Tingkat pendidikan yang rendah menyebabkan pendapatan yang diperoleh seseorang relatif rendah. Tingkat pendidikan seseorang menyangkut pengetahuan dan wawasan sebab tingkat pendidikan seseorang akan berpengaruh terhadap ketepatan dan kecepatan seseorang dalam mengerjakan sesuatu. Hal ini diperkuat oleh pendapat (Notoatmodjo,1998:28). Seperti kita tahu bahwa pendidikan

seseorang mencerminkan tingkat pengetahuan yang pernah diperoleh, karena semakin tinggi pendidikan yang ditempuh oleh seseorang maka semakin banyak pula pengetahuan yang diperoleh, dengan mempunyai pendidikan seseorang tersebut akan mampu menghadapi hidup, yaitu dengan berpendidikan seseorang tersebut dapat memperoleh pekerjaan yang dapat mencukupi kebutuhan hidupnya, dalam arti mempunyai kesempatan kerja guna untuk mencapai kesejahteraan yang diinginkan.

\section{Pengaruh Jumlah Tanggungan terhadap Minat Tenaga Kerja Wanita Bekerja di Unit Industri Bobbin}

Adapun hasil analisis regresi logistik menunjukkan bahwa variabel jumlah tanggungan tidak berpengaruh signifikan terhadap minat tenaga kerja wanita bekerja di Unit Industri Bobbin Kecamatan Arjasa Kabupaten Jember. Artinya banyak dan sedikitnya jumlah tanggungan keluarga tidak berpengaruh terhadap minat tenaga kerja wanita untuk bekerja di Unit Industri Bobbin karena hal itu dikarenakan tuntutan hidup seseorang tidak tergantung dari jumlah yang ditanggung jika wanita memiliki keluarga.

Hasil penelitian ini mendukung hasil penelitian yang dilakukan oleh Tresilo (2014) yang menyatakan bahwa jumlah tanggungan tudak berpengaruh signifikan terhadap minat bekerja kembali keluar negeri dan Anggraeni (2014) yang menyatakan bahwa jumlah tanggungan tidak berpengaruh signifikan terhadap minat bekerja kembali keluar negeri. Hal ini dikarenakan bahwa tuntutan hidup seseorang tidak tergantung dari jumlah yang di tanggung jika pihak keluarga memiliki pekerjaan.

\section{Simpulan}

Berdasarkan analisis data dan pembahasan, maka dapat disimpulkan sebagai berikut:

a. Variabel yang berpengaruh adalah: Variabel pendapatan berpengaruh negatif dan signifikan sebesar -0,00000146, variabel umur berpengaruh negatif dan signifikan sebesar $-0,163$ dan variabel pendidikan berpengaruh negatif dan signifikan sebesar -2,62 terhadap minat tenaga kerja wanita 
bekerja di Unit Industri Bobbin Kecamatan Arjasa Kabupaten Jember. Sedangkan yang tidak berpengaruh adalah variabel jumlah tanggungan.

b. Variabel yang sangat berpengaruh adalah variabel pendapatan dengan nilai koefisien -0,00000146 terhadap minat tenaga kerja wanita bekerja di Unit Industri Bobbin Kecamatan Arjasa Kabupaten Jember.

\section{Referensi}

Haryono. 2016. Analisis Faktor-faktor yang Mempengaruhi Keputusan Tenaga Kerja Melakukan Migrasi Sirkuler di Kecamatan Gayam Kabupaten Sumenep. Skripsi. FEB Universitas Jember.

Wahyuni, I,. 2016. Faktor-faktor yang Mempengaruhi Minat Migrasi Sirkuler Penduduk Kecamatan Negara Kabupaten Jembrana Skripsi. FEB Universitas Jember.

Santosom, K. 2013. Tembakau Dibutuhkan dan Dimusuhi. Jember : UPT Penerbitan Unej.
Anggraeni, K,. 2016. Analisis Faktor-faktor yang Mempengaruhi Keputusan Mantan Tenaga Kerja Indonesia di Kecamatan Tenggarang Kabupaten Bondowoso Kembali Bekerja ke Luar Negeri. Skripsi. FEB Universitas Jember.

Latumaerissa. J.R. 2015. Perekonomian Indonesia dan Dinamika Ekonomi Global. Jakarta: Mitra Wacana Media

Nasir, M. 2003. Metode Penelitian. Jakarta: Ghalia Indonesia Arikunto Suhartini.

Notoatmodjo, S. 2003. Pengembangan Sumber Daya Manusia. Jakarta: PT Rineka Cipta.

Purnomo, Didit. 2009. Fenomena Migrasi tenaga Kerja dan Perannya Bagi Pembangunan Daerah Asal: Studi Empiris di Kabupaten Wonogiri. JEP, Vol. 10 No.1 Juni 2009.

Ravenstein. 1976. The law of migration journal of historical geographi.

Simanjuntak, Payaman J. 1998. Pengantar Ekonomi Sumber Daya Manusia. Jakarta: Lembaga Penerbit Fakultas Ekonomi UI.

Tjiptohariyanto, P. 1997. Sumber Daya Manusia Dalam Pembangunan. Jakarta: LPFE-UI.

Tresilo, Y, B,. 2014. Analisis Faktor yang Mempengaruhi Minat Mantan TKI Untuk Bekerja Kembali Ke Luar Negeri Di Kabupaten Jember. Skripsi. FEB Universitas Jember.. 